\title{
Troponin Yüksekliğine Neden Olan Demir İntoksikasyonu: Ülkemizden Bildirilen İlk Vaka
}

\section{Iron Intoxication Causing Troponin Elevation: First Case Reported from Our Country}

Ayşenur Akın ${ }^{1}$,

Zafer Bağcıㄹ.

Salih Güler ${ }^{3}$,

Derya Arslan ${ }^{4}$

${ }^{1}$ Konya Eğitim ve Araştırma Hastanesi, Aile Hekimliği Ana Bilim Dalı, Konya, Türkiye

${ }^{2}$ Konya Eğitim ve Araştırma Hastanesi,

Çocuk Sağlığı ve Hastalıkları Ana Bilim Dalı, Konya, Türkiye

${ }^{3}$ Balıkesir Atatürk Şehir Hastanesi, Çocuk Hematoloji Bilim Dalı, Balıkesir, Türkiye

${ }^{4}$ Konya Eğitim ve Araştırma Hastanesi Çocuk Kardiyoloji Bilim Dalı, Konya, Türkiye

Geliş Tarihi/Received: 16 Ocak 2019

Kabul Tarihi/Accepted: 5 Eylül 2019

Yazışma Adresi: Ayşenur Akın, Konya Eğitim Araştırma Hastanesi, Aile Hekimliği Ana Bilim Dalı, Konya, Türkiye

e-posta: aknaysnr@hotmail.com

ORCID

Ayşenur Akın

https://orcid.org/0000-0002-7118-7082 Zafer Bağcı

https://orcid.org/0000-0003-4776-7236

Salih Güler

https://orcid.org/0000-0002-2398-0959

Derya Arslan

https://orcid.org/0000-0001-5385-3240

\begin{abstract}
Öz
Demir daha çok demir eksikliği anemisinde kullanılan bir ilaçtır. Demirin yüksek dozlarda kullanımı multisistemik bir etkiye neden olabilmektedir. Intoksikasyon gelişen olgularda semptomlar yutulan demirin miktarına bağlıdır. Minimum toksik doz ve ölümcül demir dozları kesin olarak bilinmemektedir. Ancak hayatı tehdit edebilecek düzeyde olan yan etkileri kalp ve karaciğer üzerinde görülmektedir. Bu makalede 16 yasında suisid amaçlı $720 \mathrm{mg} ; 12 \mathrm{mg} / \mathrm{kg} / \mathrm{doz}$ 'unda demir preperatı alan bir olgu sunuldu. Herhangi bir şikâyeti olmayan ancak klinik açıdan takip edilen hastanın taburculuğu planlanırken yapılan kontrol kan tetkiklerinde troponin değerinde yükselme görülmesi üzerine takibine devam edildi. Fizik muayene, Elektrokardiyogram (EKG), Ekokardiyografi (EKO) bulgusu olmayan ve demir şelasyon endikasyonu bulunmayan ve takibinde troponin düzeyinde gerileme saptanan hasta önerilerle taburcu edildi. Nadir görülen bir durum olan kardiyak etkilenme olması ve ülkemizden bildirilen ilk vaka olması nedeniyle ilacın toksisite durumundaki etkileri literatür eşliğinde tartışılı.
\end{abstract}

Anahtar Kelimeler: Çocuk, intoksikasyon, demir, troponin yüksekliği

\section{Abstract}

Iron is a medication that is used more in iron deficiency anemia. The use of iron in high doses can cause a multisystemic effect. The toxicity of iron depends upon the amount of elemental iron ingested. The minimum toxic dose and the lethal doses of iron are not firmly established. However, side effects that may be life-threatening are seen on the heart and liver. This paper presents a 16 -year-old patient who used $720 \mathrm{mg} ; 12 \mathrm{mg} / \mathrm{kg} /$ dose preparation of iron for suicide purposes. The control blood tests performed while planning the discharge of the patient, who had no complaints but were followed up clinically, continued to be followed up because of the increase in the value of troponin. The patient who has no record of physical examination, electrocardiogram (ECG), echocardiography (ECO) and indication for iron chelation and in whose troponin level a decrease was diagnosed in the monitoring was discharged with recommendations. Due to the rare occurrence of cardiac involvement and being the first case reported in our country, the effects of the drug on toxicity were discussed in the light of the literature.

Keywords: Child, intoxication, iron, troponin elevation

\section{GíRiş}

Demir insan ve diğer pek çok canlı türü için gerekli esansıyel bir elementtir. Kanın en önemli fonksiyonel komponentini oluşturur. Kanda hemoglobin oluşumu, oksijenin dokulara taşınması, oksidatif prosesin sürdürülmesi gibi önemli işlevler görür (1). Demir intiyacı olan hücrelerin yüzeyinde bulunan transferin reseptörü 1 aracılığı ile transferine bağlı demir, hücrelere alınır (1). İhtiyaç fazlası demir alımı vücutta toksik etkilere neden olabilmektedir. Demirin toksisitesi yutulan element demirinin miktarına bağlıdır. Minimum toksik doz ve ölümcül demir dozları kesin olarak belirlenmemiştir. Demir kaynaklı doku hasarının başlıca mekanizması, serbest radikal üretimi ve lipid peroksidasyonudur (2). Yerel toksisite de başııca gastrointestinal mukoza etkilenmektedir. 
Karın ağrısı kusma, diyare ve gastrointestinal kanama olarak ortaya çıkmaktadır. Sistemik toksisite, dolaşım sistemi ve karaciğer hasarının sonucu olarak ortaya çıkar. Demir zehirlenmesinden ölüm nedeni genellikle şok veya karaciğer yetmezliğidir (3). Aşırı demir yüküne maruziyet, kardiyovasküler etkilere neden olabilmektedir. Kardiyak etkiler, kardiyomiyopati, iletim bozukluğu, aritmiler, kalp yetmezliği ve ölümle sonuçlanabilmektedir. Demirin kardiyovasküler sistem üzerindeki etki mekanizması net değildir ancak demir aracılı reaktif oksijen türlerinin (ROS) kardiyomiyosit hasarını belirleyen en önemli patojenik mekanizma olduğu bildirilmektedir. Kalbi oluşturan tüm hücre tipleri, endotelyal hücreler de dâhil olmak üzere ROS kaynaklı hasara karşı olan duyarlılı̆̆ apopitosiz, fibrozis ve nihayetinde kardiyak disfonksiyon ile sonuçlanabilmektedir (4).

$\mathrm{Bu}$ makalede intihar amaçlı ferröz sülfat tablet kullanan 16 yaşında kız hasta, toksik dozda ilaç alımı olmamasına rağmen nadir görülen bir durum olan kardiyak etkilenme olması nedeniyle sunuldu ve ilacın toksisite durumundaki etkileri, literatür bilgileri eşliğinde tartışıldı.

\section{OLGU}

Her bir tableti 80 mg demir sülfat içeren tabletlerden intihar amaçlı 9 adet alan (toplam $720 \mathrm{mg}$ ve $12 \mathrm{mg} / \mathrm{kg} /$ doz) ve 4 saat sonra bulantı ve 1 kez kusma şikâyeti olan 16 yaşında $58 \mathrm{~kg} \mathrm{kız} \mathrm{hasta} \mathrm{acil} \mathrm{servise} \mathrm{başvurdu.}$ Öz geçmişinde demir eksikliği anemisi dışında özellik yoktu. Hastanın fizik muayenesinde genel durumu iyi, bilinci açık, koopere ve kişi yer zaman oryantasyonu tamdı. Vücut ısısı 37,0 C ,Kalp hızı:140 atım/dakika, kan basıncı 110/80 mmHg idi. Oda havasında $\mathrm{O}_{2}$ saturasyonu: $\% 99$, solunum sayısı $24 / \mathrm{dk}$ tespit edildi. Orofarenks muayenesi doğal; kardiyovasküler sistem muayenesi doğal, S1+/S2+ ritmik, ek ses ve üfürüm yoktu. Solunum sistemi muayenesi doğaldı. Batın muayenesinde epigastrik hassasiyet mevcuttu. Nörolojik sistem muayenesi doğal, meninks iritasyon bulgusu yoktu, derin tendon refleksleri normoaktif ve kas gücü tamdı. Vital takipleri taşikardisi acısından yakın takibe alınan hastanın taşikardisinin devam etmediği görüldü. Geliş taşikardisinin hastanın korku heyecan ve kusmasına bağlı olabileceği düşünüldü. Hastanın elektrokardiyografik (EKG) incelemesinde: 78 atım/dakika hızında sinüs ritminde olduğu görüldü. PR: 160 ms, QTC: 404 ms ölçüldü. İskemiyi gösteren ST /T değişikliği, AV blok veya disritmi saptanmadı. Hastanın yapılan tetkiklerinde venöz kan gazı, biyokimya, hemogram ve kardiyak (troponin I, CK,

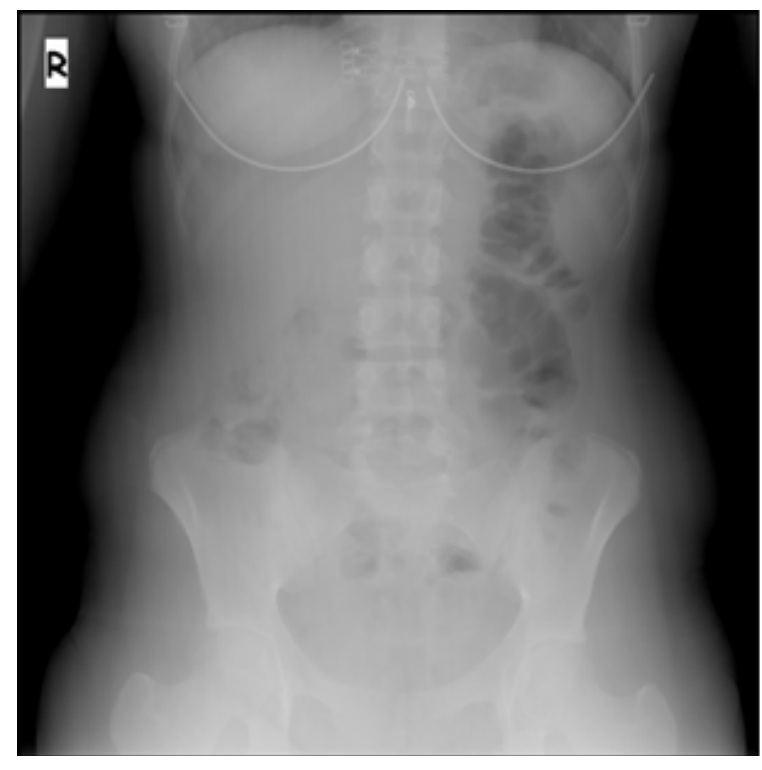

Şekil 1. Çekilen ayakta direkt batın grafisinde demir preparatları görülmemektedir

CK-MB) değerleri normal sınırlarda idi. Kanda demir düzeyi: $436 \mu \mathrm{g} / \mathrm{dl}$ (referans aralığı: 50-120 $\mu \mathrm{g} /$ dl) olarak tespit edildi. ADBG' sinde demir hapları görülmedi (Şekil 1). Hasta monitorize edilerek oral alımı kapatıldı. Tarafımıza ilaç alımıdan 4 saat sonra başvurduğu için gastrik lavaj yapılmadı. Aktif kömür etkisiz olduğu için uygulanmadı. Hasta toksik dozda (20mg/kg ) ilaç almadığı için 24 saat acil gözlem şartlarında takip edildi. Altı saat sonra kan tetkileri tekrarlandı. Demir düzeyinin $392 \mu \mathrm{g} / \mathrm{dl}$ ye gerilediği gözlemlendi. Diğer kan değerleri normal sınırlarda idi. On iki saat sonrasında yapılan tetkiklerinde, demir düzeyinin $261 \mu \mathrm{g} / \mathrm{dl}$ 'ye gerilediği görüldü. Vital takipleri (ateş, nabız, tansiyon, vücut Isısı) de stabil olan ve taburculuk planlanan hastaya oral İlaç alımından 24 saat sonra yapılan kan tetkikleri yenilendi. Demir düzeyinin $64 \mu \mathrm{g} / \mathrm{dl}$ 'e gerilediği ancak troponin I değerinin $0.44 \mathrm{ng} / \mathrm{ml}$ (referans aralığı: 0.0-0.2 ng/ $\mathrm{ml}$ ) olduğu görüldü. Aktif şikayeti olmayan hastanın EKG incelemesinde iskemi bulgusu yoktu. Geliş elektrokardiyografik incelemesi ile uyumlu idi. Kalp hızı: 74 atım/dakika sinüs ritmi, PR:160 ms, QTC: 405 ms ölçüldü (Şekil 2).Hastanın acil gözlemde takibi devam etti. Dört saat sonra troponin I ve EKG kontrolü yapıldı. Troponin I $0.45 \mathrm{ng} / \mathrm{ml}$ tespit edildi, şikâyeti olmayan hastaya ekokardiyografi (EKO) planlandı. EKO'da patolojik bulgu saptanmayan hasta kardiyak monitorizasyon altında takip edildi. 4 saat sonra kan 


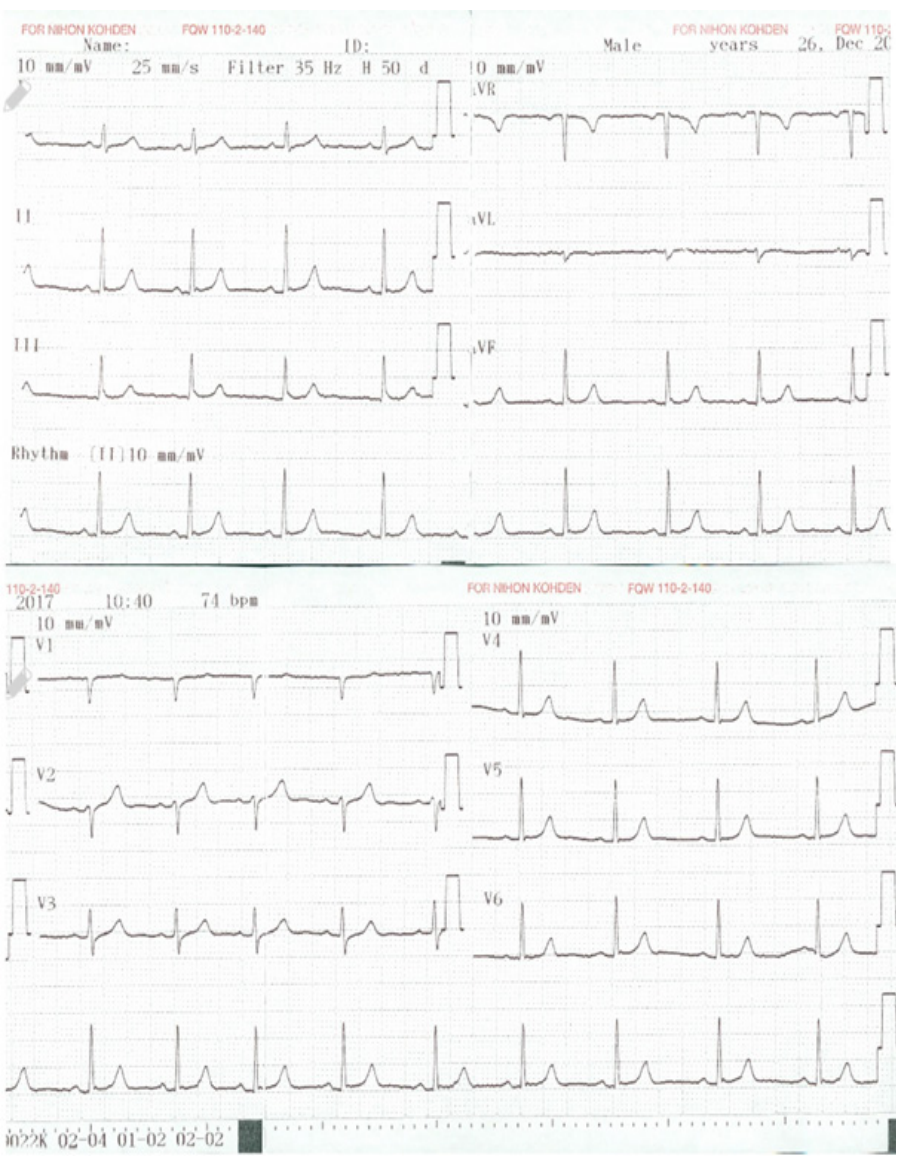

Şekil 2. Hastanın elektrokardiyografik incelemesinde patoloji görülmemektedir. Sinüs ritmindedir.

tetkikleri yeniden yapıldı. Troponın I düzeynin 0.26 $\mathrm{ng} / \mathrm{ml}$ düzeyine gerilediği; demir düzeyinin $35 \mu \mathrm{g} / \mathrm{dl}$ düzeyine gerilediği görüldü. Aktif şikâyeti olmayan hasta günlük kan tetkik kontrolüne gelmesi önerilerek ve çocuk psikiyatri görüşü alınarak taburcu edildi. Hastanın bir gün sonra yapılan EKG'sinde patalojik bulgusu olmaması, troponin I düzeyinin $0.19 \mathrm{ng} / \mathrm{ml}$ düzeyine gerilemesi üzerine hasta takipten çıkarıldı.

\section{TARTIŞMA}

Demir preperatları başlıca demir eksikliği anemi tedavisinde kullanılmaktadır. Demirin yüksek dozlarda kullanımı multisistemik etkiye neden olabilmektedir. Demir toksisitesi sıklıkla birbiriyle örtüşen beş fazda tanımlanır; ilk 6 saate kadar gastrointestinal faz, ilk 24 saate kadar latent faz, ilk 72 saate kadar şok ve metabolik asidoz fazı, ilk 96 saate kadar hapatotoksisite ve hepatik nekroz fazı ve 8 haftaya kadar görülebilen intestinal obstrüksiyon evresidir
(5-7). Hayatı tehdit edebilecek düzeyde olan yan etkileri kalp ve karaciğer üzerinde görülür $(8,9)$. İlk birkaç saat içinde ortaya çıkan sıvı ve kan kaybından kaynaklanan hipovolemik şok, 24-48 saat içinde demirin miyokard hücreleri üzerindeki depresan etkisinden dolayı kardiyojenik şok, demirin pasif olarak hepatosit hücrelerinden emiliminden kaynaklı hepatoksisite, sarılık, koma, koagülopati, DíC (Dissemine İntravasküler Koagülasyon) ve karaciğer yetmezliğine bağlı ölüm gelişebilmektedir. Literatürde 21 aylık bir hastada kazara 1.5-3 gr demir sülfat, 150-300 mg fenobarbital, $75-150 \mathrm{mg}$ metamfetamin aldığı bilinen hastada şok, koma, nöbetler, hematemez, hipofibrojenemi, aspirasyon, konjensif kalp yetmezliği gelişip 42. saatte tüm destekleyici bakım ve desferroksamin tedavisine rağmen öldüğü bildirilmiştir. Hastanın klinik bulguları demir toksisitesi bulgurlarıyla uyumlu bulunmuştur(10). Literatürde yakın tarihte demir intoksikasyonu nedeniyle kardiyak etkilenme olgusu bildirilmemiştir. Ancak fareler üzerinde yapılan birçok çalışma demirin miyokart hücreleri üzerinde toksik etki oluşturduğu gösterilmiştir. Bu etkisinin hücre ölümü, fibrozis, sonuçta sistolik ve diyastolik fonksiyon bozukluğuna yol açan lipid peroksidasyonuna ve organel hasarına neden olan ROS üretimini katalizleme özelliğinden kaynaklandığı gösterilmiştir (11-13).

Bulantı kusma şikâyeti ile gelen hastamızda sinüs ritmi mevcuttu. Elektrokardiyografik değerlendirmede düzeltilmiş QT süresi 404 msn olarak normal değerlendirildi. Kan tetkiklerinde ve EKG değerlendirmesinde patoloji yoktu. İdrar multidrug tetkikinde ek ilaç kullanımı saptanmadı. Aktif şikâyeti olmayan hastanın takip süresinin 24 . Saatinde yapılan kontrol kan tetkiklerinde troponin düzeyinde artış görüldü. Demir intoksikasyonu sonucu kardiyak etkilenim olabileceği şüphesiyle kardiyak acıdan düzenli kardiyak monitorizasyon ve EKG takibi yapılarak EKO planlandı. Klinik açıdan değişiklik olmayan hastanın yapılan ekokardiyografik incelemesinde patoloji görülmedi. Hastada bakılan troponin değerinin demir aracılı reaktif oksijen türlerinin (ROS) kardiyomiyosit hasarına bağlı olarak yükselmiş olabileceği düşünüldü. Benzer şekilde, miyokart enfarktüsü, karbon monoksit zehirlenmesi, hipoksi gibi durumlarda da myosit hasarına bağlı olarak troponin yükselmesi izlenmektedir.

$\mathrm{Bu}$ ilacın yüksek dozda kullanımına bağlı toksisite gelişmesi durumunda gastrointestinal dekontaminasyon yapılmalı ancak emilimi etkilemediği için aktif kömür verilmesi önerilmemektedir. Gastrik 
lavaj ilaç yutulduktan ilk bir ila iki saat içinde başvuran hastalarda uygulanmalıdır. Tam bağırsak irrigasyonu ciddi demir aşırı dozda etkili bir gastrointestinal dekontaminasyon yöntemidir. Abdominal radyografiyle görüntülenen gastrointestinal sistemde önemli sayıda hap bulunan tüm hastalar için bağırsak irrigasyonu başlatılmalıdır. Ayrıca tedavide intravenöz hidrasyon yapılmalı, radyografik olarak ilaç miktarı belirlenmesi ve gastrik lavajın etkinliğini değerlendirmek için tekrarlayan batın grafisi çekilmelidir. Hipovolemi, şok letarji ve sürekli kusma ve ishal gibi şiddetli semptomları olan; anyon açıklıklı metabolik asidozu olan;500 mcg/dl den daha yüksek serum demir konsantrasyonu olan ve abdominal radyografide önemli sayıda hap görülen hastalarda demir şelasyon tedavisi yapılmalıdır (11-13). Ekstrakorporeal demir giderme yöntemleri (örn: Hemodiyaliz), yalnızca serbest dolaşan demiri çıkardıkları ve hücre içi demir transportu gerçekleşmeden önce; yutulmasından hemen sonra başlatılmaları gerektiği için etkinlik bakımından sınırıdır. Kan transfüzyonu veya sürekli veno-venöz hemofiltrasyon ile ekstrakorporeal uzaklaştırma, klinik bozulmanın devam ettiği ve deferoksamin uygulamasına rağmen serum demir düzeylerinin çok yüksek kaldığı masif aşırı doz aşımı vakalarında kullanılabilmektedir(14). Şelasyon endikasyonu bulunmayan hastalar için takip süresi 24 saattir. Hastamız ilaç alımından 4 saat sonra acil servisimize başvurduğu için gastrik lavaj yapılmadı. Aktif kömür verilmedi. Sadece bulantı ve kusma şikâyeti olan hastamıza hidrasyon tedavisi yapılarak klinik açıdan takip edildi.

Sonuç olarak demir eksikliği anemi tedavisinde kullanılan demir preperatlarının uygunsuz kullanımına bağlı toksisite gelişmesi durumunda genel olarak serum demir konsantrasyonu ( $\mathrm{Fe}$ ), serum elektrolitleri ( $\mathrm{Ca}, \mathrm{Mg}, \mathrm{P}, \mathrm{Na}, \mathrm{K}$ ), üre, kreatin, glikoz, alanin ve aspartat aminotransferazlar (ALT-AST) ve bilirubinler venöz veya arteryel kan gazı, hemogram, protrombin zamanı (PT), aktive parsiyel tromboplastin zamanı (APPT) bakılmaktadır. Fakat bu olgu sunumu da göstermiştir ki klinik açıdan bulgu olmamasına rağmen demir intoksikasyonunda kardiyovasküler etkilenim olabileceği unutulmamalı; kardiyomiyosit hasarını gösteren paremetre olan troponin ölçümleri mutlaka yapılmalı ve hasta kardiyak etkilenim açısından takip edilmelidir.

Çıkar Çatışması: Çalışmada herhangi bir çıkar çatışması yoktur.

Finansal Çıkar Çatışması: Çalışmada herhangi bir finansal çıkar çatışması yoktur.

Yazışma Adresi: Ayşenur Akın, Konya Eğitim Araştırma Hastanesi, Aile Hekimliği Ana Bilim Dalı, Konya, Türkiye E-mail:aknaysnr@hotmail.com

\section{KAYNAKLAR}

1. Kayaalp SO. Antianemik ilaçlar. Kayaalp SE(ed). Akılcıl Tedavi Yönünden Tıbbi farmakoloji. Pelikan Yayıncılık 20121503.

2. Tenenbein M. Toxicokinetics and toxicodynamics of iron poisoning. Toxicol Lett 1998;102-3:653-6.

3. Black J, Zenel JA. Child abuse by intentinoal iron presenting as shock and persistent acidosis. Pediatrics 2003;111(1):1979.

4. Lekawanvijit S, Chattipakorn N. Iron overload thalassemic cardiomyopathy: Iron status assessment and mechanisms of mechanical and electrical disturbance due to iron toxicity. Can J Cardiol 2009;25(4):213-8.

5. Mills KC, Curry SC. Acute iron poisoning. Emerg Med Clin North Am 1994;12(2):397-413.

6. Klein-Schwartz W, Oderda GM, Gorman RL, et al. Management guidelines. Acute iron ingestion. Clin Pediatr (Phila) 1990; 29(6):316-2.

7. Velez, L, Delaney, K. Heavy metals. In: Marx, J, Hockberger, R, Walls, R (eds). Emergency Medicine: Concepts and Clinical Practice. 5th edition, St. Louis: Mosby, 2006. p.2418.

8. Tenenbein M, Israels SJ. Early coagulopathy in severe iron poisoning. J Pediatr 1988; 113(4):695-7.

9. Rosenmund A, Haeberli A, Straub PW. Blood coagulation and acute iron toxicity. Reversible iron-induced inactivation of serine proteases in vitro. J Lab Clin Med 1984;103(4):52433.

10. Greenblatt DJ, Allen MD, Kock-Weser J. Iron poisoning in childhood: Six cases including one fatality. Clin Pediatr (Phila) 1976;15(9):835-8.

11. Gammella E, Recalcati S, Rybinska I, et al. Iron-induced damage in cardiomyopathy: Oxidative-dependent and independent mechanisms. Oxid Med Cell Longev 2015;2015:230182.

12. Ávila RA, Silva MASC, Peixoto JV, et al. Different concentrations of ferrous iron in the rat myocardium. Toxicol In Vitro 2016;36:38-45.

13. Madiwale T, Liebelt E. Iron: Not a benign therapeutic drug. Curr Opin Pediatr 2006;18(2):174-9.

14. Milne $C$, Petros $A$. The use of haemofiltration for severe iron overdose. Arch Dis Child 2010; 95:482. 